\title{
Incidence and risk factors of acute coronary syndrome in younger age groups
}

\author{
Abhishek Sharma*, Yasser Chomayil, Firoz Abdul Karim, Venugopalan Poovathum Parambil \\ From EMCON 2014: International Conference on Emergency Medicine; 16th Annual Conference by the \\ Society for Emergency Medicine in India (SEMI) \\ Mumbai, India. 6-9 November 2014
}

\section{Objectives}

Acute Coronary Syndrome (ACS) is one of the major causes of mortality and morbidity globally. The incidence of ACS in the younger population is rising; hence, there is a need for more careful evaluation and proper disposition of this subset population.

This study determines the incidence, risk factors and mortality of Myocardial Infarction (STEMI \& NSTEMI) among hospitalized patients presenting to the ED with chest pain ages 40 years or less.

\section{Methodology}

Patient-records were reviewed and collected from the Medical Record Department and analyzed in terms of variables such as risk factors, type of MI, and mortality.

This was a retrospective study of all patients who presented to the ED and were admitted with a diagnosis of Myocardial Infarction at MIMS Kottakkal over a span of 2 years (August 2012- August 2014). All patients aged 18-40 presenting to ED with a complaint of chest pain / discomfort and admitted with a diagnosis of myocardial infarction were included, and patients with congenital cardiac defects were excluded.

\section{Results}

A total of 955 patients were admitted with Myocardial Infarction in these 2 years, out of which 37 patients (3.9\%) fulfilled the inclusion criteria. The mean age was 36.14 years, Male:Female ratio was found to be 8:1 . Incidence of AWMI, IWMI, NSTEMI and LWMI were $36.2 \%, 33.33$ $\%, 30.5 \%$ and nil cases respectively. The risk factors in our patients were dyslipidemia, smoking, diabetes and hypertension, \& family history.

* Correspondence: abhidollar@gmail.com

MIMS Kottakkal, Kerala, India

(c) 2015 Sharma et al; licensee Springer. This is an Open Access article distributed under the terms of the Creative Commons Attribution License (http://creativecommons.org/licenses/by/4.0), which permits unrestricted use, distribution, and reproduction in any medium, provided the original work is properly cited.

\section{Conclusion}

Healthcare providers should be vigilant and have a high index of suspicion when dealing with patients presenting with chest pain less than 40 years old than to discharge them as non-cardiac pain without appropriate evaluation and workup.

Published: 22 April 2015

doi:10.1186/1865-1380-8-S1-P4

Cite this article as: Sharma et al:. Incidence and risk factors of acute

coronary syndrome in younger age groups. International Journal of Emergency Medicine 2015 8(Suppl 1):P4.
Submit your manuscript to a SpringerOpen ${ }^{\bullet}$ journal and benefit from:

- Convenient online submission

Rigorous peer review

- Immediate publication on acceptance

- Open access: articles freely available online

- High visibility within the field

- Retaining the copyright to your article

Submit your next manuscript at $>$ springeropen.com 